\title{
COMPRESSIVE STRENGTH AND RHEOLOGY DEPENDENCY ON MICRO SILICA DOSAGE IN ULTRA-HIGH-PERFORMANCE CONCRETE
}

Ernests Ozolins $^{1}$, Juris Zavickis ${ }^{2}$, Arturs Lukasenoks ${ }^{1}$, Arturs Macanovskis ${ }^{3}$

${ }^{1}$ Betona pêtījumu centrs, Latvia; ${ }^{2}$ Dzelzsbetons MB, Latvia; ${ }^{3}$ Riga Technical University, Latvia ernests.ozolins@bpcentrs.lv, juris.zavickis@mbbetons.lv, arturs.lukasenoks@ rtu.lv, arturs.macanovskis@rtu.lv

\begin{abstract}
Ultra-high-performance concrete (UHPC) is a new and innovative concrete material associated with very high strength, low permeability to aggressive environment and self-compact ability. These characteristics enable innovative engineering solutions to be applied in practice which would have previously been thought to be impossible to manufacture. Many previous studies suggest relatively high dosage rates of micro silica (MS) (25\% by weight of binder (wtob)). This paper focuses on optimizing and studying how the MS addition to UHPC affects the compressive strength and overall rheological properties of UHPC. The study was performed by doing compressive strength tests as well as concrete slump flow tests to evaluate the rheology and slump flow over a period of time to evaluate how well the mix retains its initial rheological properties. It was found that the compressive strength was enhanced the most by $3.75 \%$ by wtob of MS substitution. The best rheology for selfcompact ability was obtained by substituting MS between $5 \%$ and $7.5 \%$ by wtob. It was also found that increase an in MS dosage rate will reduce the open life of fresh concrete.
\end{abstract}

Keywords: Ultra-high-performance concrete, rheology, compressive strength.

\section{Introduction}

Ultra-high-performance concrete (UHPC) has been defined by its high compressive strength, dense structure, low capillary porosity and self-levelling behaviour [1]. The Low water-to-cement ratio is key to obtaining these properties. However, in UHPC, it is more beneficial to maintain a set water-to-binder ratio and to lower the water to ultra-fines (all of the particles smaller than 125 micrometres) ratio instead, for improved compressive strength [2]. To optimize the packing density, amorphous silica particles in from of micro silica (MS), also known as silica fume, are introduced into the mix [3]. These are a byproduct of industrial silicon production and have their particle size distribution in the micrometre range and have a characteristically high specific surface area $[4 ; 5]$.

There are two main reaction processes for strength improvement that should be considered in UHPC containing MS:

- The surface of the silica particles act as a nucleation point or seed for the formation of calcium silicate hydrate phases produced by the hydration process. This in turn reduces the initial energy barrier for the nucleation process to occur, the filler effect $[3 ; 4 ; 6-8]$.

- Pozzolan reaction between silica and calcium hydroxide (a by-product of the cement hydration process), creating calcium silicate hydrate phases (C-S-H). These are found to behave similarly to compounds made from the cement hydration process, but the reaction starts only approximately 3 days after placing concrete $[4 ; 6-8]$.

The spherical characteristics of the silica particles help to replace water that might otherwise be trapped in the space between smaller and larger particles in the mix. This in turn can reduce the viscosity of the mix thus improving its rheological properties as well as reducing porosity and making the microstructure denser $[3 ; 4 ; 6]$. With an increased rate of silica fume addition, it is expected that the benefits of recouped water will diminish due to the high surface area of silica particles and the subsequent increase in water demand [4]. At the point at which the surface area of MS particles overcomes the surface area of cement particles, MS particles become the dominant adsorbent of PCE molecules. This makes the SP less effective at dispersing cement particles if the SP is optimized for cement particle dispersion [9]. This will lead to reduced slump flow of concrete which in turn leads to increased entrapped air volume and porosity in self-consolidating concretes [9-11].

Previous studies with MS addition in UHPC have indicated an optimal MS addition of $20 \%$ to $30 \%$ by the weight of binder (wtob) [12]. However, recently it has been shown that the biggest improvement from MS addition in the UHPC matrix is at the dosage rate of 5\% by wtob as shown in Fig. 1. Moreover, a decrease in compressive strength with increased MS dosage in concretes with low water-to-binder ratios has been observed $[4 ; 6]$. This can be attributed to the fact that UHPC generally has a low water- 
to-cement ratio of less than 0.25 . This ensures that the cement hydration process is incomplete, thus not supplying enough calcium hydroxide for the pozzolan reaction of silica to continue, thus the strength gain potential from MS addition is not fully fulfilled [3]. This is one of the main reasons why previous studies of MS dosage rate effect on the strength of ordinary concrete cannot be directly translated into the same effectiveness in UHPC. It is thus suggested that the filler effect in UHPC will be more efficient at increasing the compressive strength than the pozzolan reaction of MS [3; 8]. In addition to this, it has been shown that silica particles initially increase the rate of nucleation. But over time they poison and retard the growth and nucleation of calcium hydroxide crystals at an increased silica dosage between $10-20 \%$ by wtob, whilst being beneficial for the crystal nucleation and growth at lower dosages $[8 ; 13]$.

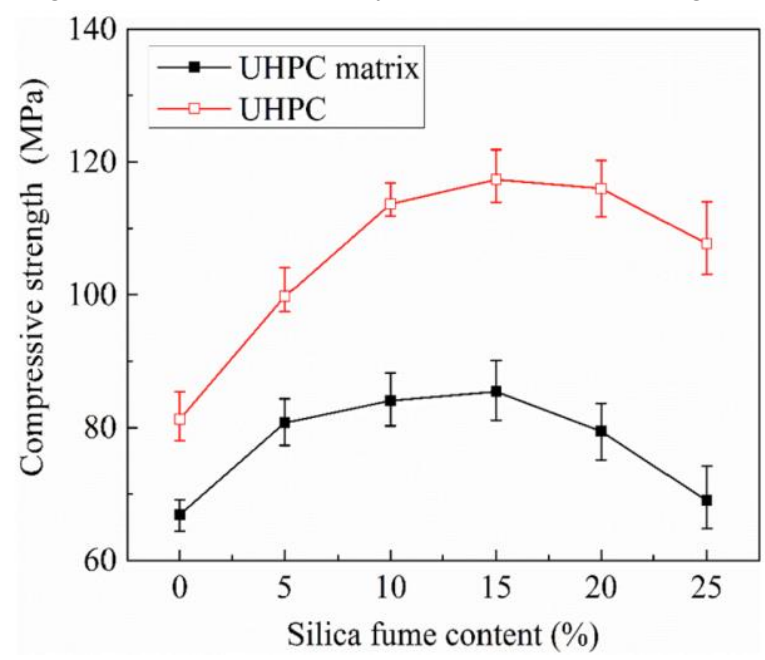

Fig. 1. Compressive strength of UHPC matrix and UHPC with varying silica fume content [4]

A more recent study found that the quickest rate of hydration, 5 hours after placing the sample, was for concrete with 5-8\% by wtob substitution rate of MS. However, the initial rate of reaction of up to 5 hours after placing the concrete was higher the more MS was added [8], suggesting that concrete with more MS will have a shorter workable life. It was also confirmed that the pozzolanic reaction, which occurs at the diffusion stage of the hydration process, only starts to react 3 days after the sample has been made [8]. It is thus suggested that any strength gain that might be noticeable in the 2-day compressive strength test can be contributed to the seeding effect of MS.

As MS is an expensive addition to UHPC this study aims to find the most efficient use of this resource by looking at a lower dosage rate of MS effect on UHPC rheology and strength characteristics.

\section{Materials and methods}

The following materials were used in the study:

- Aalborg white cement as the primary binder (Specific gravity of 3.15, mean particle diameter of $12.7 \mu \mathrm{m}$ and specific surface area of $\left.1676 \mathrm{~m}^{2} \cdot \mathrm{kg}^{-1}\right)$;

- Elkem micro silica 940U (Specific gravity - 2.2, mean particle diameter $-0.316 \mu \mathrm{m}$, a specific surface area greater than $\left.15 \mathrm{~m}^{2} \cdot \mathrm{g}^{-1}\right)$;

- test optimized mix of 4 quartz fractions from our previous study with a specific gravity of 2.612 and maximum grain size of $1.25 \mathrm{~mm}$ [14];

- acrylic polymer-based superplasticizer (SP) with $30 \mathrm{wtob} \%$ solid content Mapei Dynamon SX130 ;

- tap water.

The MS was dosed as a percentage replacement of cementitious binder in the mix in small increments as shown in Table 1. The SP dosage and water to binder ratio of 0.25 were kept constant throughout the study, in order to quantify what effect on the properties does the addition of MS has without any additional changes to the mix itself. That lead to a constant dosage of water and SP, $191.6 \mathrm{~kg} \cdot \mathrm{m}^{-3}$ and $12 \mathrm{~kg} \cdot \mathrm{m}^{-3}$ respectively. 
For precise measurements, scales (LW Measurements HRB series scales) with the accuracy of up to $0.1 \mathrm{~g}$ were used to weigh quartz, cement and MS. Scales with a precision of up to $0.01 \mathrm{~g}$ (SF-400C) were used to weigh water and SP for tests.

Table 1

UHPC mix proportions used in this study

\begin{tabular}{|c|c|c|c|}
\hline Reference & Cement, $\mathbf{~ k g} \cdot \mathbf{m}^{-3}$ & $\begin{array}{c}\text { Micro silica, } \mathbf{~ k g} \cdot \mathbf{m}^{-\mathbf{3}} \mathbf{( \%} \\
\text { of binder) }\end{array}$ & $\begin{array}{c}\text { Optimized quartz } \\
\text { fraction, } \mathbf{~ k} \cdot \mathbf{~ m}^{-3}\end{array}$ \\
\hline MS - 0 & 800 & $0(0 \%)$ & 1380.2 \\
\hline MS - 10 & 790 & $10(1.25 \%)$ & 1376.7 \\
\hline MS - 20 & 780 & $20(2.5 \%)$ & 1373.1 \\
\hline MS - 30 & 770 & $30(3.75 \%)$ & 1369.5 \\
\hline MS - 40 & 760 & $40(5 \%)$ & 1365.9 \\
\hline MS - 50 & 750 & $50(6.25 \%)$ & 1362.3 \\
\hline MS - 60 & 740 & $60(7.5 \%)$ & 1358.8 \\
\hline MS - 70 & 730 & $70(8.75 \%)$ & 1355.2 \\
\hline MS - 80 & 720 & $80(10 \%)$ & 1351.6 \\
\hline MS - 90 & 710 & $90(11.25 \%)$ & 1348.0 \\
\hline MS - 100 & 700 & $100(12.5 \%)$ & 1344.4 \\
\hline MS - 110 & 690 & $110(13.75 \%)$ & 1340.9 \\
\hline
\end{tabular}

Zero point six litres of concrete were made for each batch of tests. Concrete was mixed in a HOBART Laboratory Mortar Mixer. All four sand fractions are put in the mixer first and mixed until a homogeneous mix is obtained. Then cement and MS are added to the mixer and it is further mixed for another 2 minutes. After that, a mixture of water and the required SP dosage is poured into the mixer. The concrete is then mixed for a further 10 minutes.

The slump flow test was done in accordance with ASTM C230 standard with a modification to the size of the cone, which was (Top diameter $-70 \mathrm{~mm}$, bottom diameter $-100 \mathrm{~mm}$, height $-60 \mathrm{~mm}$, as shown in Fig. 2). The time it takes for concrete to reach $20 \mathrm{~cm}$ in diameter, T20 time, as well as the maximum slump flow diameter, $D_{\max }$, were measured.

Samples for compressive strength testing were made using prisms with dimensions 40x40x160 mm, concrete was poured in one go and no additional compaction was done. From each testing batch, 2 prisms were made. Before compressive strength tests, the prism samples were cut into 3 pieces each with 40x40x40 mm. The curing and compressive strength, and density measurements of the samples were done in accordance with EN 12390 standard. Two samples were tested at 2 and 7 days of age, and the remaining 2 samples were tested at 28 days.

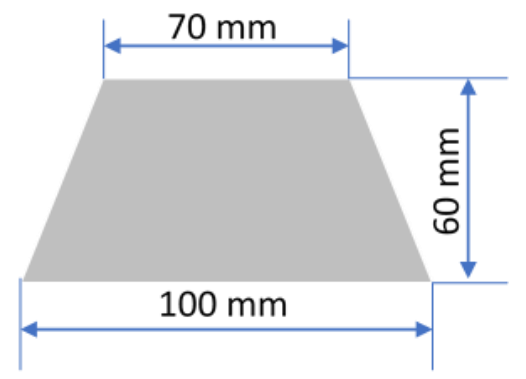

Fig. 2. Dimensions of the cone used for the slump flow tests

Slump flow retention tests were done in a similar manner, but with a smaller cone size for reduced volume requirements (Top diameter $-30 \mathrm{~mm}$, bottom diameter $-45 \mathrm{~mm}$, height $-45 \mathrm{~mm}$, as shown in Fig. 3). For this test, the container with concrete in it was covered to ensure no excess water evaporates from the mix. The slump flow was tested every 30 minutes and only the maximum slump flow diameter was recorded.

Error bars in Figures represent the accuracy with which the results were obtained. For direct measurements such as slump flow in $\mathrm{cm}$ and time in minutes or seconds, the error bars indicate the 
possible deviation in the measurement. The slump flow was measured with an accuracy of $0.5 \mathrm{~cm}$, time was measured with an accuracy of 2 minutes or 1 second depending on the measurement. The error bars in graphs for compressive strength and density comparison, represent the overall deviations in the obtained results. Error bars thus show the maximum and minimum obtained value for all of the similar samples tested.

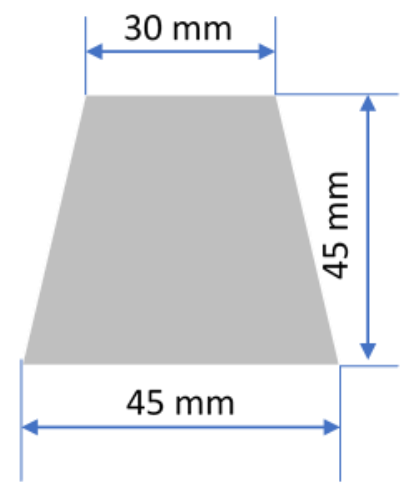

Fig. 3. Dimensions of the cone used for slump flow retention tests

\section{Results and discussion}

The slump flow retention test results show a clear relationship between increased MS dosage and reduction in the length of the open life of the mix. From the results, it can be approximated that by substituting $1.25 \%$ of the binder by MS, the open life will be reduced by 30 minutes. The results also indicate that the loss of workability over time can be thought of as directly proportional to MS dosage, for dosages between $2.5 \%$ and $7.5 \%$ by wtob, as can be seen in Fig. 4. The reduction in open life can be contributed to the increase in early hydration rate right after mixing when additional MS is added due to the filler effect.

The results also show that the maximum slump flow is achieved at different times depending on the MS dosage, showing that the SP reacts differently when MS is added to the mix. Increased MS dosage will eliminate the delayed increase in slump flow.

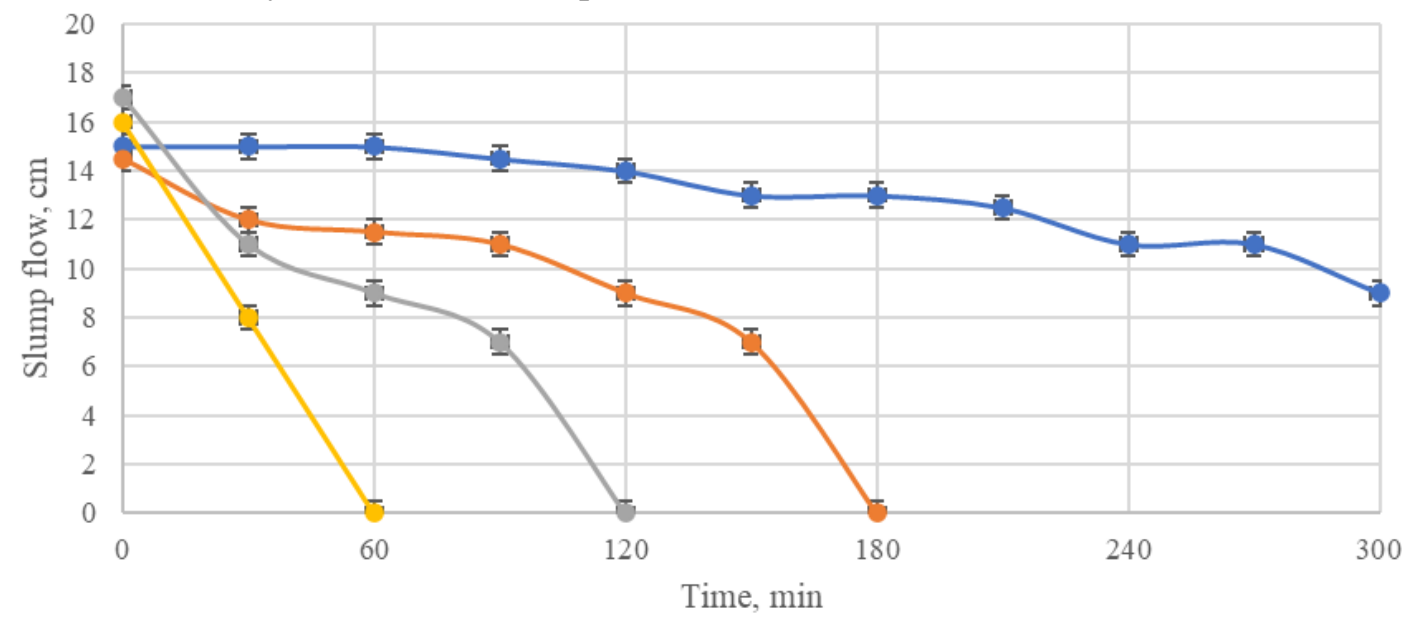

-0 wtob $\%$ of MS -2.5 wtob $\%$ of MS -5 wtob $\%$ of MS -7.5 wtob $\%$ of MS

Fig. 4. Slump flow of UHPC mixes with differing MS dosage over time

The slump flow test showed that the lowest viscosity, measured by T20 time of 3 seconds was achieved by mixes containing $5-7.5 \%$ by wtob of MS. Further addition or reduction in the substitution rate leads to an increase in viscosity.

At low substitution rates, it is clear that MS acts as a filler for the voids within the mix and to reduce the friction between particles due to its small particle size, thus lowering the viscosity. However, when 
more than $7.5 \%$ by wtob of MS is added to the mix, the water consuming effect of increased surface area due to MS particles takes over and increases the viscosity of the concrete mix.

The maximum slump flow value was marginally improved by the addition of $1.25 \%$ by wtob of MS to the mix. However, there was not a significant increase when more MS was added, indicating that MS has an insignificant effect on the maximum slump flow characteristics of UHPC. A tipping point was achieved when the substitution rate of MS was increased above $10 \%$ by wtob, as that lead to a sharp decrease in the maximum slump flow. At that stage, the negative effects of the increased surface area of the added MS particles overcome the positive filler effect and require more water or SP to achieve the same slump flow. This might be explained by the fact that at this point, as is shown in Fig. 6 the surface area of MS particles becomes greater than that of cement particles, thus MS becomes a major constituent in the mix. This leads to SP polymers adsorbing mostly on the surface of MS particles instead of cement particles leading to a decrease in dispersion and increase viscosity.

Overall, the results indicate that major negative effects of MS substitution on fresh concrete rheology appear when the substitution rate is increased above $10 \%$ by wtob. Other researchers also agree that the addition of MS of $10 \%$ by wtob or more will lead to reduced workability of the mix. They also agree that the optimal dosage of MS is within the range of 5-10\% by wtob [5].

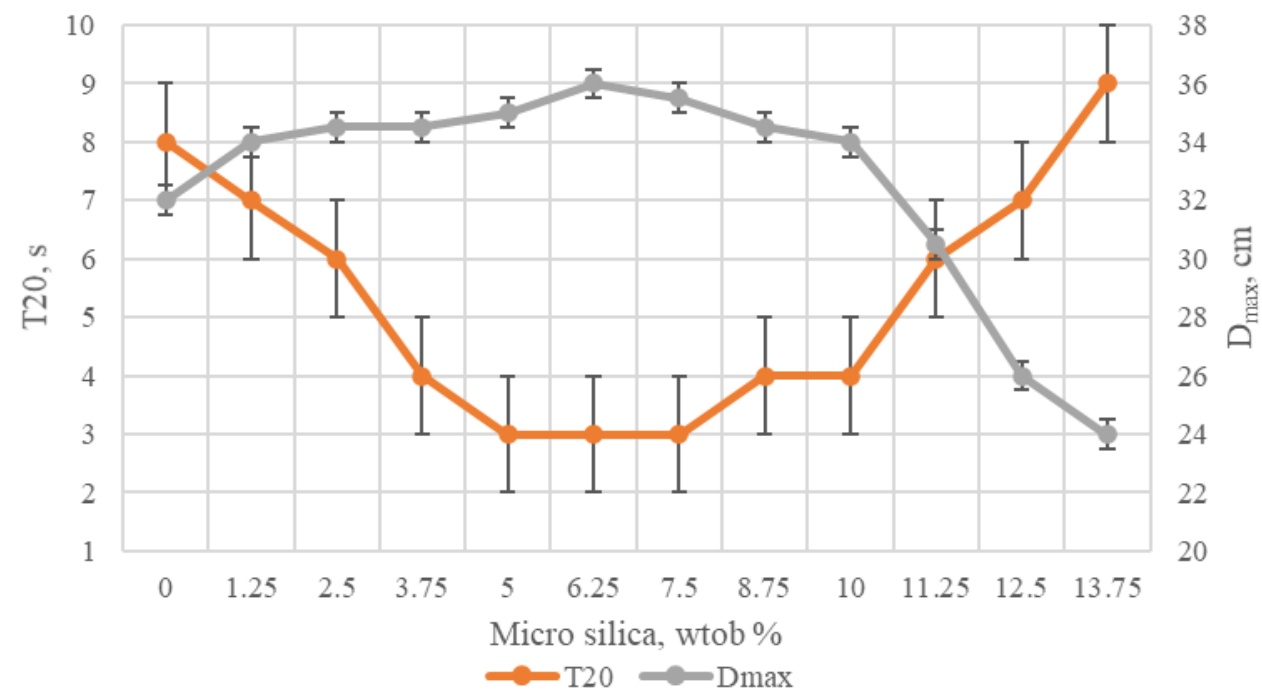

Fig. 5. Slump flow T20 and $D_{\max }$ values for the UHPC mixes with varying MS substitution rate

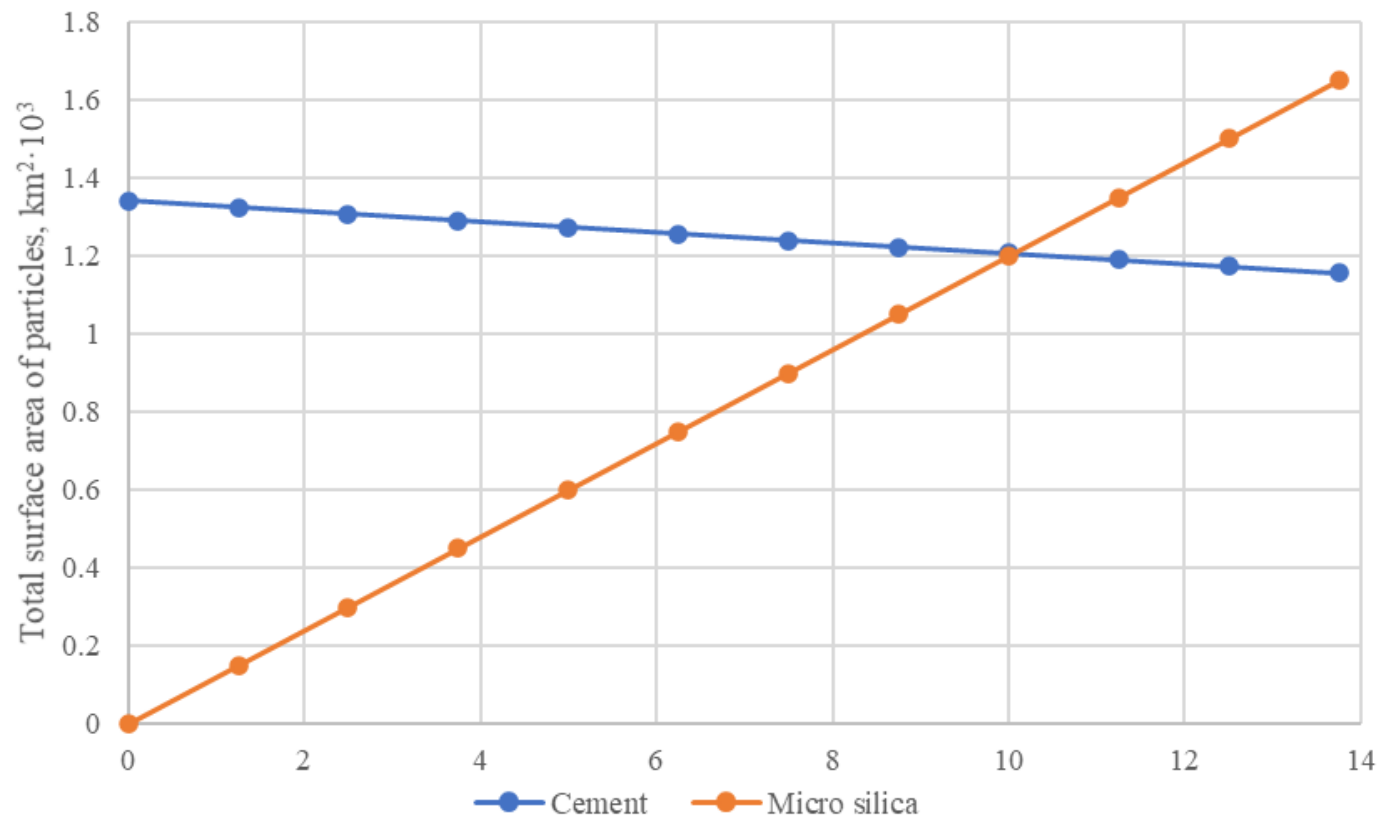

Fig. 6. The surface area of cement and micro silica particles in $\mathbf{m} 3$ of concrete depending on the micro-silica dosage 
Compressive strength tests showed that there is a significant improvement in the early age strength at 2 days when increasing the substitution rate of MS from $1.25 \%$ to $2.5 \%$ by wtob. The maximum early strength was $15.6 \%$ higher when compared to baseline with no MS, which is obtained at the dosage rate of $6.25 \%$ by wtob. The increase in strength can be attributed to the seeding effect MS has on the mix. It is acting as the initiator, catalyst for a quicker hydration process as well as the fact that at this dosage the UHPC mix exhibited the best rheology parameters as seen in Fig. 5.

Statistical analysis of the obtained results lead to the development of a mathematical model for the compressive strength dependency on the addition of MS to the mix presented in Fig. 8 and Fig. 9. The $\mathrm{R}$ factor for the 2-day compressive strength model is 0.879 and for the 28-day strength, it is 0.6093 indicating the soundness of the obtained results.

Researchers agree that the addition of MS to concrete will lead to improved compressive strength at an early age and at 28-days as is shown in the results [3; 4]. It is also agreed that better rheology facilitates better particle dispersion and thus improved mechanical properties [11].

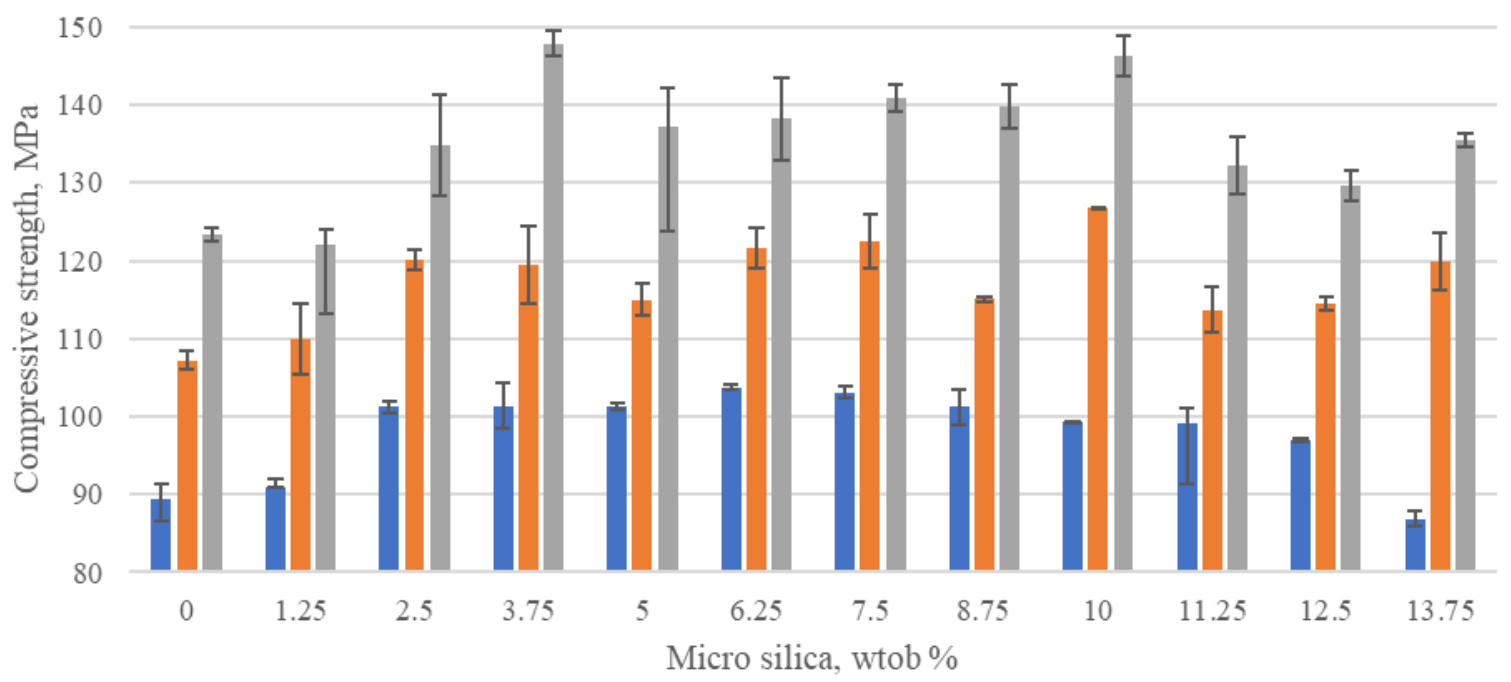

$\square 2 \mathrm{~d}=7 \mathrm{~d}=28 \mathrm{~d}$

Fig. 7. Compressive strength of UHPC concrete specimens with different micro silica dosages at ages of 2,7 and 28 days

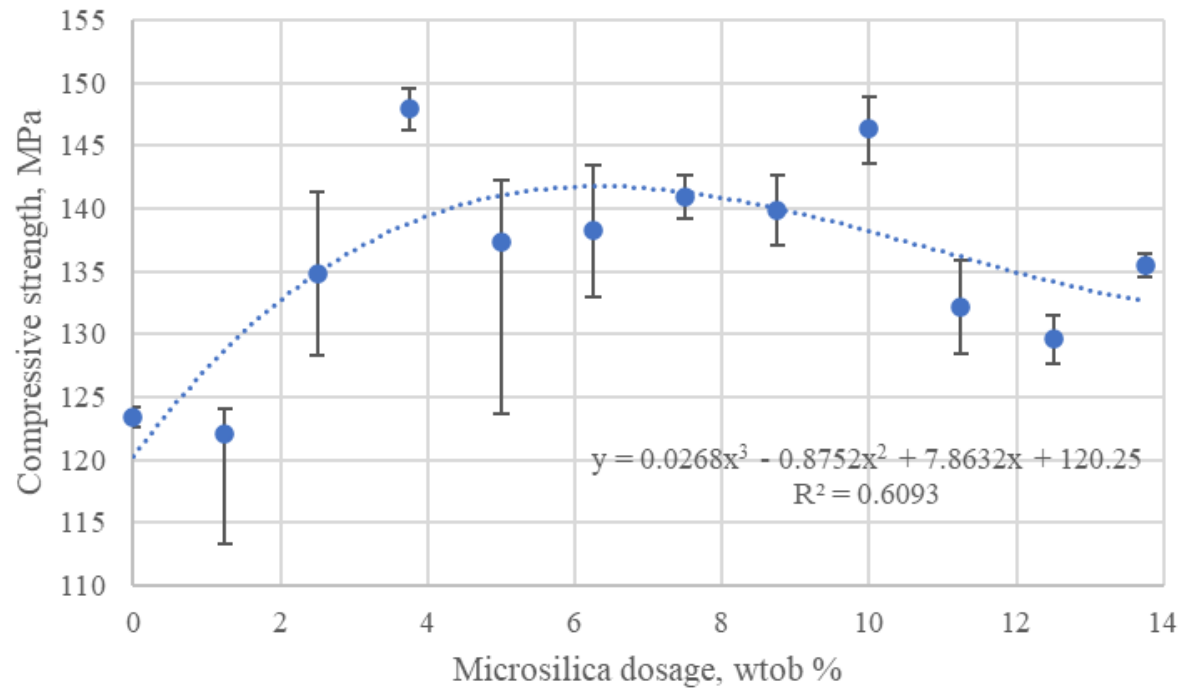

Fig. 8. Regression analysis of the 28-day compressive strength depending on the micro-silica dosage 


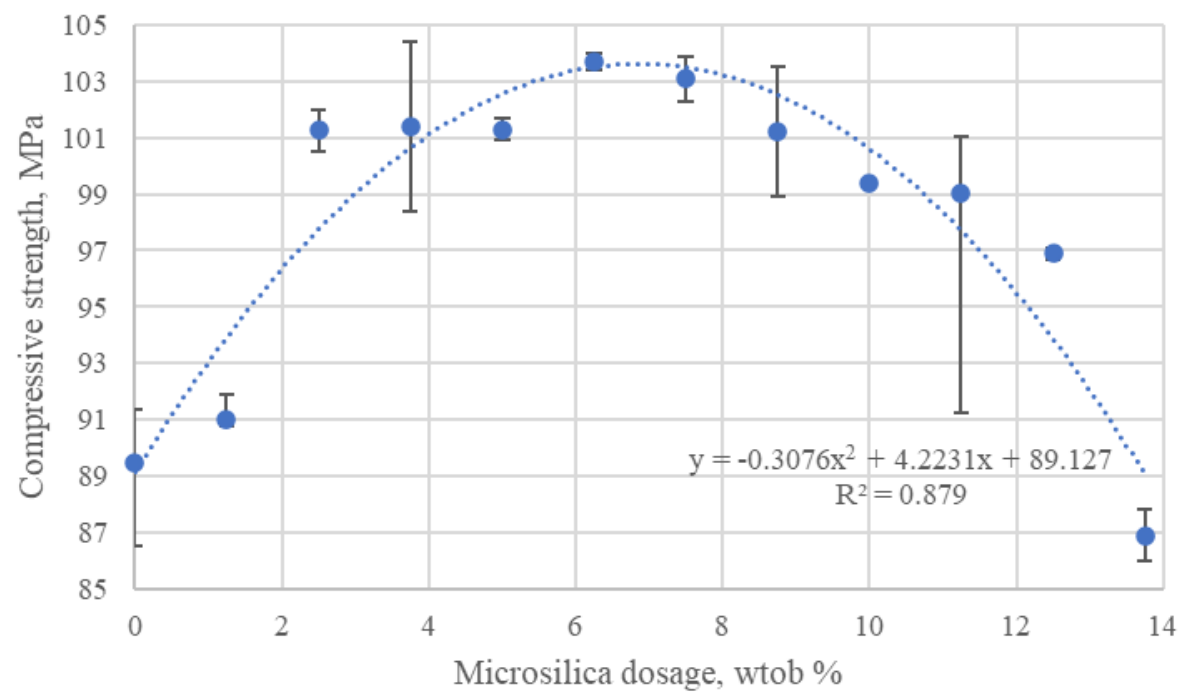

Fig. 9. Regression analysis of the 2-day compressive strength depending on the micro-silica dosage

At the age of 7 days, the relative strength increase was similar between most of the dosages as can be seen in Fig. 10. However, a slight reduction in the strength gain was noticed over 0 and $8.75 \%$ by wtob MS dosages. A sharp increase in the relative strength gain was obtained for samples with 10 and $13.75 \%$ by wtob of MS indicating accelerated pozzolanic reaction taking place. With that, the highest strength was obtained at $10 \%$ by wtob dosage, reaching $127 \mathrm{MPa}$, which is an $18.7 \%$ improvement when compared to the base mix.

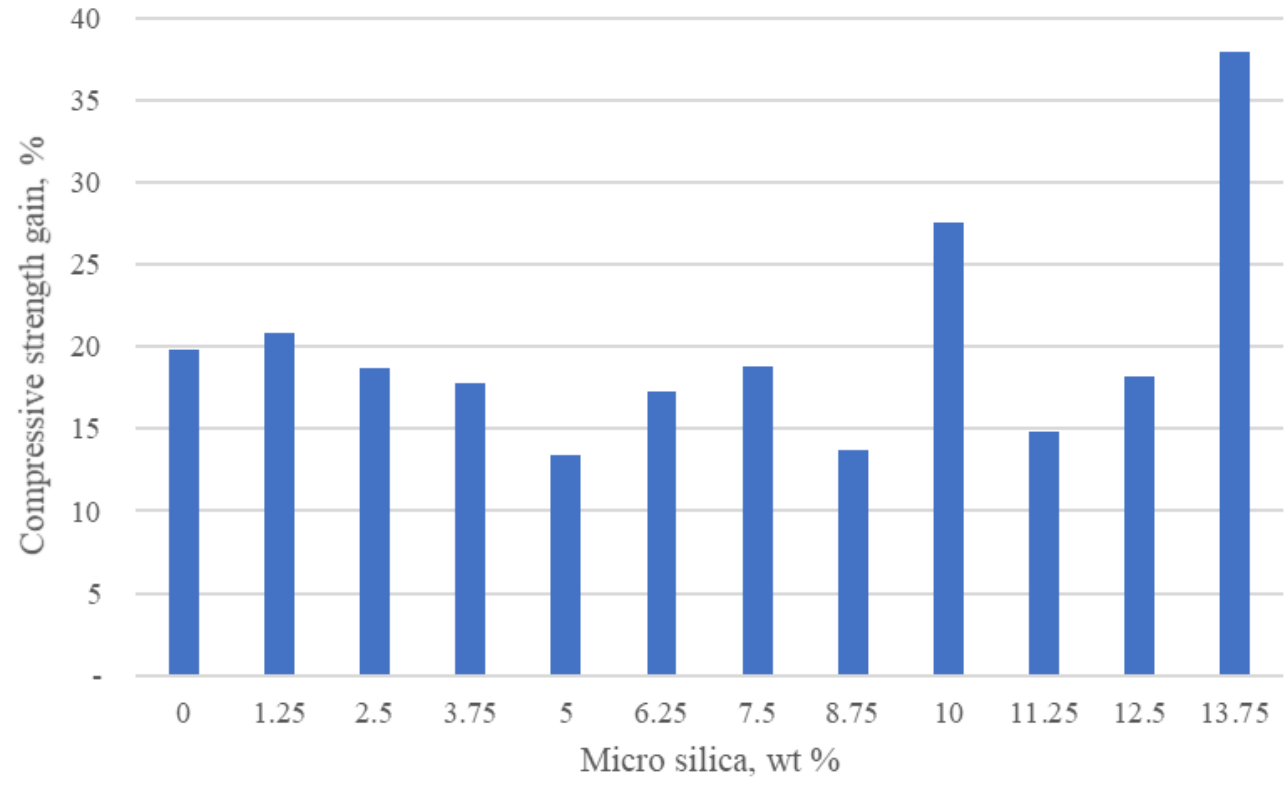

Fig. 10. Relative compressive strength gain between the tests made at $\mathbf{2}$ and $\mathbf{7}$ days

The relative strength gain reaches a maximum at $3.75 \%$ by wtob dosage rate of MS, as shown in Fig. 11. It can also be seen in Fig. 11 that the strength gain is then gradually reduced with an increase in the MS dosage, eventually becoming worse than for the baseline mix. Interestingly, there is a reduction in the relative strength gain observed when compared to the baseline for dosages of 1.25 and $2.5 \%$ by wtob. This might be due to increased strength gain during the early age hydration and thus a slower increase in strength during later stages due to an insufficient amount of silica for pozzolanic reaction to be effective. These results thus indicate that there is a critical amount of silica necessary for the pozzolanic reaction to be effective. However, after reaching the critical amount, the pozzolanic reaction may become quicker, start sooner, but becomes less effective at increasing the compressive strength of concrete as is evident in Fig. 11. 


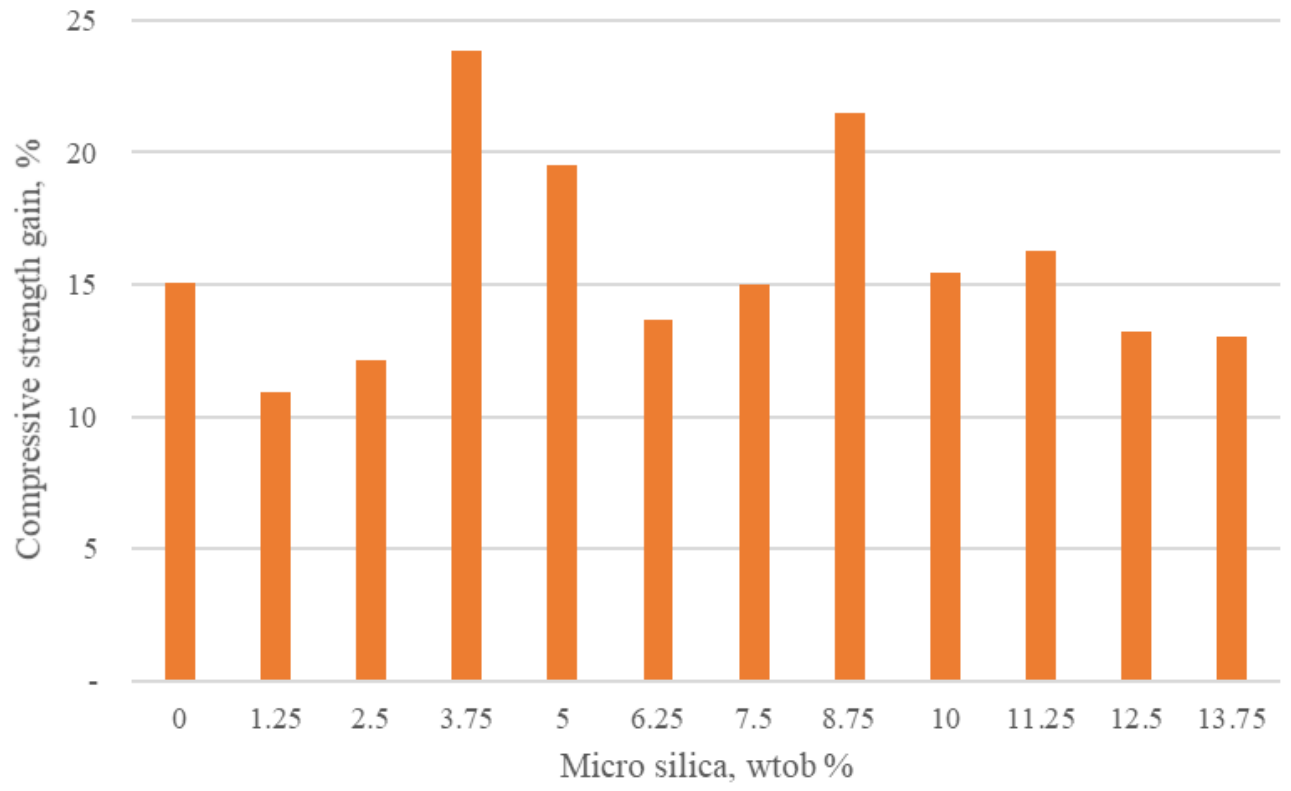

Fig. 11. Relative compressive strength gain between the tests made at 7 and 28 days

A decline in the early age strength, as well as strength at 7 and 28 days of the age of the samples, can be noticed when the MS substitution rate exceeds $10 \%$ by wtob. This correlates with a decrease in density of concrete at this dosage of MS as can be seen in Fig. 12. Completing a regression analysis on the obtained results lead to the development of a mathematical equation for the calculation of density of the concrete depending on the MS dosage shown in Fig. 12. The obtained R-factor was 0.614 indicating the soundness of the results. There are several factors that contribute to the decrease in density. Fig. 5 shows an increase in viscosity of the mix at this dosage rate, thus making it more likely that air bubbles will be trapped within the sample, thus increasing the porosity which leads to a reduction in strength.

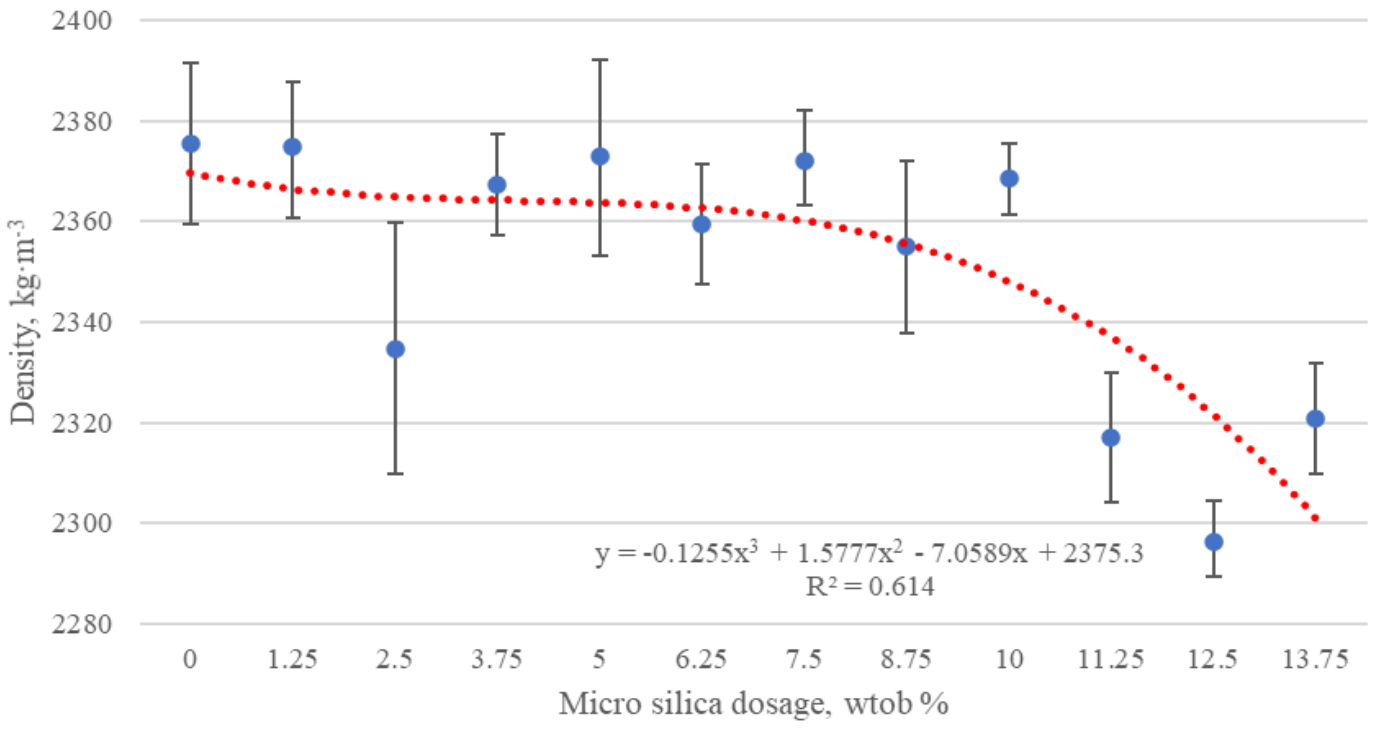

Fig. 12. The density of UHPC samples at 28 days with varying micro silica dosage

The concrete strength reaches a maximum at $3.75 \%$ by wtob replacement rate with MS at 28 days. The results show that the 28-day compressive strength is reduced if more than $3.75 \%$ by wtob of MS is added to the mix. As can be seen in Fig. 13, the biggest improvement in compressive strength per percentage of MS added is at the dosage rate of $3.75 \%$ by wtob with the lower dosage of $2.5 \%$ by wtob being the second-best option. This suggests that the most efficient use of MS in this particular case is at the dosage rate of $3.75 \%$ by wtob as that maximizes the seeding effect as well as the benefit from pozzolanic reaction whilst obtaining sufficient workability. 


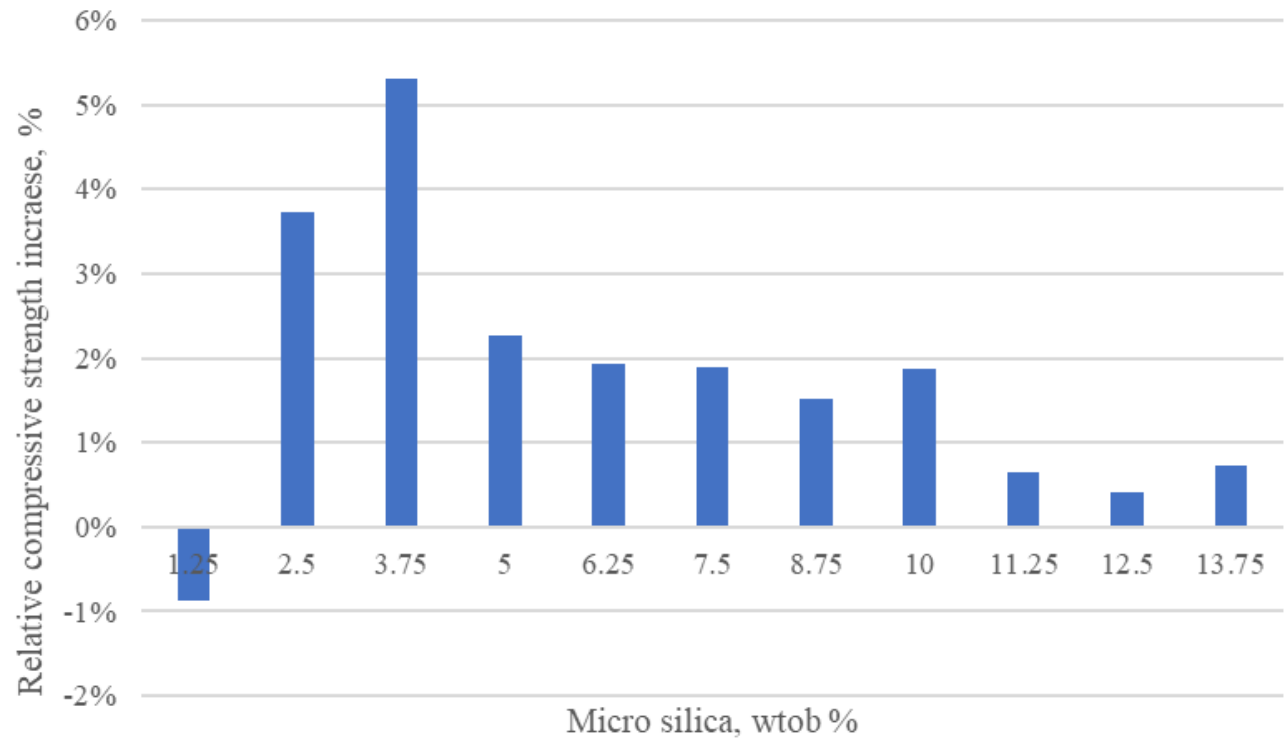

Fig. 13. Relative compressive strength gain per wtob\% of MS addition at different MS dosage rates

\section{Conclusions}

1. The highest compressive strength was achieved with MS dosage rate of $3.75 \%$ by wtob with a $20 \%$ increase in compressive strength when compared to a mix with no MS added to it.

2. The best rheological properties of the concrete were achieved at dosage rates between $5 \%$ and $7.5 \%$ by wtob.

3. Addition of MS reduces the open life of a UHPC mix, possibly due to an increased early hydration rate.

4. Important consideration for rheological properties of UHPC is the greatest particle surface area present in the mix. If SP is optimized for cement particle dispersion, then, once the MS particle surface area becomes greater than that of the cement particles, rheological properties will be affected, and SP will become less efficient at particle dispersion at a fixed SP dosage rate.

5. The most efficient use of MS for the best compressive strength improvement in the developed mix is at the dosage rate of $3.75 \%$ by wtob.

\section{Acknowledgements}

In accordance with the contract No. 1.2.1.1/18/A/007 between "Competence centre of smart materials and technologies" Ltd. and the Central Finance and Contracting Agency, concluded on 23rd of April, 2019, the study is conducted by "Dzelzsbetons MB" Ltd. with support from the European Regional Development Fund (ERDF) within the framework of the project "Competence centre of smart materials and technologies".

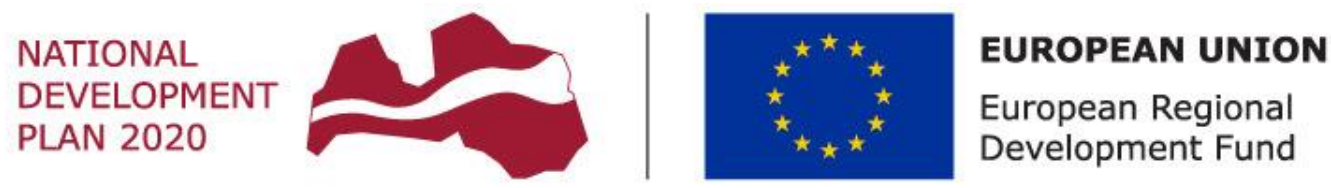

$$
\text { I N VESTING IN YOUR FUTURE }
$$

\section{References}

[1] de Larrard F., Sedran, T. Optimization of ultra-high-performance concrete by the use of a packing model. Cement and Concrete Research, vol. 24(6), 1994, pp. 997-1009.

[2] Fehling E., Walraven, J., Leutbecher Torsten., Schmidt, M., Fröhlich, S. Ultra-High Performance Concrete UHPC. Berlin: Ernst \& Sohn/A Wiley Brand, 2014. 
[3] Oertel T., Hutter F., Tänzer R., Helbig U., Sextl G. Primary particle size and agglomerate size effects of amorphous silica in ultra-high performance concrete. Cement and Concrete Composites, vol. 37, 2013, pp. 61-67.

[4] Wu Z., Khayat, K., Shi, C. Changes in rheology and mechanical properties of ultra-high performance concrete with silica fume content. Cement and Concrete Research, vol. 123, 2019, p.105786.

[5] Bahrami N., Zohrabi, M., Mahmoudy, S., Akbari, M. Optimum recycled concrete aggregate and micro-silica content in self-compacting concrete: Rheological, mechanical and microstructural properties. Journal of Building Engineering, vol. 31, 2020, p.101361.

[6] Rao G. Investigations on the performance of silica fume-incorporated cement pastes and mortars. Cement and Concrete Research, vol. 33(11), 2003, pp. 1765-1770.

[7] Oertel T., Hutter F., Helbig, U., Sextl, G. Amorphous silica in ultra-high performance concrete: First hour of hydration. Cement and Concrete Research, vol. 58, 2014, pp. 131-142.

[8] Zelić J., Rušić D., Veža D., Krstulović R. The role of silica fume in the kinetics and mechanisms during the early stage of cement hydration. Cement and Concrete Research, vol. 30(10), 2000, pp. 1655-1662.

[9] Plank J., Schroefl C., Gruber M., Lesti M., Sieber R. Effectiveness of polycarboxylate superplasticizers in ultra-high strength concrete: the importance of PCE compatibility with silica fume. Journal of Advanced Concrete Technology, vol. 7(1), 2009, pp. 5-12.

[10] Szwabowski J., Łaźniewska-Piekarczyk B. Air-entrainment problem in self-compacting concrete. Journal of Civil Engineering and Management, vol. 15(2), 2009, pp. 137-147.

[11] Arora A., Aguayo M., Hansen H., Castro C., Federspiel E., Mobasher B. and Neithalath N. Microstructural packing- and rheology-based binder selection and characterization for Ultra-high Performance Concrete (UHPC). Cement and Concrete Research, vol. 103, 2018, pp. 179-190.

[12] Wille K., El-Tawil S., Naaman A. Properties of strain hardening ultra high performance fiber reinforced concrete (UHP-FRC) under direct tensile loading. Cement and Concrete Composites, vol. 48, 2014, pp. 53-66.

[13] Brown P., Galuk K., Frohnsdorff G. The rate of calcium hydroxide precipitation measured by electrical conductance. Cement and Concrete Research, vol. 14(6), 1984, pp. 843-846.

[14]Zavickis J., Lukasenoks A., Macanovskis A., Tupesis M. Optimization of packing of local coarse aggregates for use in UHPC (Ultra-High-Performance Concrete). 19th International Scientific Conference Engineering for Rural Development Proceedings, 2020. 